\title{
Keeping Humans in the Loop: Pooling Knowledge through Artificial Swarm Intelligence to Improve Business Decision Making
}

\author{
Lynn Metcalf ${ }^{1}$, David A. Askay ${ }^{1}$, and Louis B. Rosenberg ${ }^{2}$ \\ ${ }^{1}$ California Polytechnic State University, San Luis Obispo, CA, USA \\ ${ }^{2}$ Unanimous AI, San Francisco, CA
}

Summary

This article explores how a collaboration technology called Artificial Swarm Intelligence (ASI) addresses the limitations associated with group decision making, amplifies the intelligence of human groups, and facilitates better business decisions. It demonstrates of how ASI has been used by businesses to harness the diverse perspectives that individual participants bring to groups and to facilitate convergence upon decisions. It advances the understanding of how artificial intelligence (AI) can be used to enhance, rather than replace, teams as they collaborate to make business decisions.

Keywords: artificial swarm intelligence, artificial intelligence, human swarms, group decisionmaking, crowdsourcing, wisdom-of-the-crowd, prediction markets, collective intelligence, human-in-the-loop AI

A growing body of research demonstrates how artificial intelligence (AI) is helping humans make better decisions. ${ }^{1}$ In particular, AI relies on advances in machine learning, creating value by analyzing very large data sets, and delivering insights to decision makers, thereby improving and accelerating the decision-making process. Examples of how machine learning AI 
can be leveraged by decision makers range from gleaning market insights about customers to providing more accurate medical diagnoses. ${ }^{2}$ Along with these advances in machine learning comes the fear that human workers will soon be replaced by machines or will rely too heavily on guidance from machines without having access to the underlying algorithms that produced the guidance. Diverging from the dominant discourse that predicts the rise of machines, emerging research is beginning to explore the ways in which AI can elevate human capabilities rather than replace them.

Machine learning AI is centered on making predictions informed by massive amounts of existing data that can be codified, stored, and manipulated by computers. The type of knowledge that can be processed by computers is called explicit knowledge, and machine learning extrapolates from explicit knowledge that is known. Yet, when confronted with real problems, businesses often find that adequate historical data are not available for many important decisions: What are our strategic priorities? Should we enter a new market? What product should we launch? How do we accurately forecast sales for a new product? Which design creates the better user experience? In fact, for these types of business decisions, which are called known unknowns, groups of humans can perform rather well. ${ }^{3}$ Decisions such as these often require and benefit from tacit knowledge — unique knowledge that individuals possess but cannot articulate. ${ }^{4}$ Tacit knowledge takes on several forms and includes deep-seated knowledge that people are unaware that they have and how they acquired it, but can access in order to solve problems and make decisions. ${ }^{5}$ Tacit knowledge includes personal experience, skills, perceptions, intuition, mental models, beliefs, and feelings. ${ }^{6}$ Unlike explicit knowledge (facts, procedures, and routines), which can be articulated, codified, stored, and processed, tacit knowledge can be difficult to convert into words or numbers and thereby difficult to transfer to others in a discussion or to codify for 
machine learning purposes. ${ }^{7}$ While humans have access to both explicit and tacit knowledge, lack of access to tacit knowledge and the reliance on historical data from which patterns can be identified are major limiting factors of AI that is predicated on machine learning. ${ }^{8}$ Machine learning can only work off of the codified information to which it has access.

Broader strategic questions require knowledge that cannot be reduced to and captured by data alone. ${ }^{9}$ If optimal business performance is dependent on both explicit and tacit knowledge, how might we get beyond the limitations of machine learning AI and bring humans with all of their knowledge—-both explicit and tacit—into the loop? ${ }^{10}$ When machines and people are connected in the right ways, they can achieve greater intelligence and make better decisions. ${ }^{11}$ The purpose of this article is to describe how Artificial Swarm Intelligence (ASI) - a form of AI that is not predicated solely on machine learning — can harness and amplify the knowledge, wisdom, and insights of human groups to make more effective predictions and decisions that involve known unknowns.

ASI draws from the methods of achieving collective intelligence found in biological swarms to enable human groups to form a single emergent intelligence. ASI provides the means for networked individuals to combine their explicit and tacit knowledge in real time and to work synchronously to make predictions, to assess alternatives, and to reach decisions about known unknowns. When enabled by ASI, human swarms form a collectively intelligent system that can outperform traditional methods of dealing with known unknowns, including machine learning AI. ${ }^{12}$ Moreover, ASI enables dozens, hundreds, or potentially thousands of people to combine their insights simultaneously and to successfully reach decisions as a unified system. This article demonstrates how groups of humans, when enabled by computing, can pool their intelligence and function as a Supermind - a "powerful combination of many individual minds" - to address 
known unknowns. ${ }^{13}$ Indeed, it is this type of collaborative arrangement between humans and machines where businesses have achieved the largest performance improvements. ${ }^{14}$

To introduce the ASI approach to making decisions about known unknowns, we introduce the biological models and theory upon which ASI is based. Then, we contrast ASI with other approaches to harnessing the collective intelligence of groups to address known unknowns. Through extended case examples, we demonstrate how human swarms can reach decisions that exceed the accuracy of traditional methods of pooling intelligence, but also include the perspectives of all group members. In doing so, we offer an optimistic picture of the future of AI - one that brings groups of diverse people together and amplifies human intelligence by capitalizing on what humans do well, which is to bring their unique explicit and tacit knowledge to bear on known unknowns.

\section{ASI: Mimicking Nature to Facilitate Human Superminds}

Schools of fish, flocks of birds, colonies of ants, and swarms of bees exhibit collective intelligence, in that they are capable of making decisions that extend beyond the knowledge of individuals in the group. ${ }^{15}$ As they confront known unknowns (e.g., where to find food or where to locate a hive), individuals within the group base their decisions on self-organized local interactions with group members. ${ }^{16}$ The kind of self-organization enabled by these multi-agent systems — whether they are composed of bees, ants, or fish — enables the swarm to amplify intelligence and to suppress errors, while collaborating to converge upon solutions (e.g., identifying a food source or a hive location) that are optimized for the collective. ${ }^{17}$ The improved performance that arises from distributed, self-organized decision making is defined as swarm intelligence. $^{18}$ 
Business systems that mimic swarm behavior have been around for decades and have been used to solve optimization problems like freight logistics, routing in telecommunication networks, and planning workflow in distribution warehouses. ${ }^{19}$ Swarm intelligence systems that enable drones to self-organize as a coherent and coordinated group have been modeled after flocking birds and the synchronized movements of robot systems have been modeled on schools of fish. ${ }^{20}$ While these types of AI systems have many useful applications, the emergent decisionmaking process found in honey bee swarms provides a powerful analog for how human brains arrive at complex decisions and has informed the development of ASI, which enables groups of networked humans to function as a unified intelligence and to make complex and nuanced decisions about known unknowns that draw from the explicit and tacit knowledge of all group members. $^{21}$

As a means of understanding how ASI enables humans to operate as a unified intelligence, we summarize briefly the well-studied collective decision-making process of honey bees, which use swarm intelligence to reach decisions when scouting and selecting a suitable location for a new colony. ${ }^{22}$ Hundreds of individual scout bees search a large area for potential sites, and then deliberate as a closed-loop system to select a location, with each participant influencing the collective decision of the group through body vibrations that encode the direction and distance to possible colony sites along with the strength of support for that site, as well as stop signals that inhibit other dancers. This process of real-time negotiation over competing signals continues until a quorum emerges that favors a particular site. ${ }^{23}$ Optimal decisions are reached by the swarm over $80 \%$ of the time. ${ }^{24}$

Recent developments in interface design, networking, and AI processing make it possible to mimic the decision process used by honey bees and to facilitate human swarming. Such 
software permits humans to explore options collectively in a decision space though an interface, while the AI engine processes in real time the input or behavioral data that humans provide. This produces an intelligent system composed of networked participants, where each participant contributes unique tacit and explicit knowledge in parallel with other participants, as the group makes a decision that is optimized for the collective. The following describes a specific implementation of ASI, called Swarm AI®, to illustrate how such a system works.

As shown in Figure 1, the system enables members of a networked decision-making group to access the swarm interface through their own computers or mobile devices. The interface includes a bar at the top that poses the decision to be considered and a graphic that plots response options at points around a hexagon. Participants each provide input by moving their own U-shaped graphical magnets with a mouse, touchpad, or touchscreen to maneuver the graphical puck toward their preferred option on the hexagon. The interface requires users to engage with the system physically by manipulating the magnet, which has been shown to encourage the expression—-through gestures and conduct—of tacit knowledge. ${ }^{25}$ Once the puck in the center of the decision space is in play, swarm participants are given up to 60 seconds to converge on an option. Individuals exert influence on the group by pulling their magnets away from alternatives they do not support toward alternatives that their unique knowledge supports. Figure 1 shows the starting state for all participants in a swarm. For illustration purposes, the participants' magnets are visible; however, when a swarm session is running, participants cannot see other participants' magnets and are responding only to the movement of the puck, which can limit herding behavior brought on by information cascades and social influence. ${ }^{26}$

The input from each individual is not a vote for a particular option but a continuous stream that varies with the individual's intent over time. Movements of all participants' magnets 
and the resulting force each participant is exerting on the puck are processed by the AI engine every 250 milliseconds and fed back into the system. The AI algorithms implicitly determine each participant's confidence [Insert Figure 1] score at every moment in time based on their behaviors (i.e., how they move their magnet), rather than by asking them to self-report confidence on an abstract scale. ${ }^{27}$ In turn, the aggregation of these confidence scores then determines how the puck should move at that moment. In this way, the AI algorithms are responsive to the behaviors of swarm members and the swarm members are responding to the emergent dynamics of the system as a whole. By adjusting the position and orientation of their graphical magnets with respect to the moving puck, participants simultaneously express their own tacit and explicit knowledge and respond to the combined tacit and explicit knowledge of the collective, which is expressed via the movement of the puck. The AI engine and the swarm interface enable complex deliberations to take place in real time, which capitalize on the pooled intelligence available in the swarm. ${ }^{28}$

Since the puck is in motion throughout the decision period, users need to re-evaluate continuously their individual knowledge about the question being asked and update the position and orientation of their magnets accordingly. ${ }^{29}$ This is significant, as it requires all participants to be engaged throughout the deliberation process. If a swarm participant stops moving their magnet in relation to the changing position of the puck, the distance between the puck and their magnet grows and their influence wanes. Importantly, all members of the swarm have equal and simultaneous capacity to influence and to respond to the intent of the group, which limits the herding behaviors that can impair group decision making. ${ }^{30}$ Anonymity eliminates leaders and followers, so that the decision reached by the swarm reflects all of the tacit and explicit knowledge available in the group. Swarm participants can exert initial force on the puck so that it 
almost converges on one response option; then, as the swarm deliberates in real time, participants with stronger confidence in another response option may exert influence on the puck so that it changes direction, moves toward, and converges upon a different response. This makes it difficult for swarm participants to be herded into an end state, since the end state cannot be inferred from what participants can see in the interface.

The ASI interface is completely flexible. Decision makers can either populate the hexagon with response options for swarm participants or they can use "suggestion mode" and start with a completely blank hexagon. Suggestion mode opens a dialog box, which enables swarm participants to suggest the response options that they would like to populate around the hexagon. Since ASI enables only six choices at a time, in order to prevent choice overload, suggestion mode can also be followed by a "top that" mode. This means that members of a swarm can suggest six options and then pick one, using suggestion mode. If "top that" mode is turned on, then another dialog box opens at the end of the first decision and asks: "Can we top that answer?" This enables swarm members to propose five more response options, which they would then evaluate against the response option that won the last round-yielding six response options. Swarm members can repeat the "top that" mode for as long as desired, going through dozens and dozens of suggestions - with the best bubbling to the top.

\section{ASI and Machine Learning AI}

ASI permits large numbers of humans to collaborate and to make decisions that draw upon both the explicit and tacit knowledge without requiring explicit communication. Individuals within the swarm base their decisions on interactions with group members via the puck. As noted previously, the Swarm AI ${ }^{\circledR}$ engine processes in real time (every 250 milliseconds) the input or 
behavioral data that humans provide. Movements of all participants' magnets and the resulting force exerted on the puck are processed by the Swarm AI ${ }^{\circledR}$ engine and fed back into the system. The Swarm AI ${ }^{\circledR}$ engine does not train on subject-specific data. Instead, it trains on human behaviors, evaluating the actions, reactions, and interactions of participants in real time as they push and pull in response to others. As long as the participants are all human, the system does not need to be re-trained when it changes to a new application. Emerging research demonstrates that, by pooling all of the intelligence available in a swarm, ASI enables human groups to make surprisingly optimized decisions and accurate predictions about problems that are known unknowns. ${ }^{31}$

In contrast, machine learning $\mathrm{AI}$ excels at finding patterns in datasets of digitized (explicit) information and facilitates decisions based on what is known. Traditional machine learning AI engines are trained using subject-specific data. For example, to diagnose chest $\mathrm{x}-$ rays, a machine learning AI system must be trained on hundreds of thousands of $\mathrm{x}$-rays that are very similar. To use that same AI system to forecast sales, the system would have to be trained on historical sales data and the context for all of those historical sales data needs to be similar (e.g., no changes in competitors, economic conditions, or products).

Human swarms have outperformed machine learning AI. As an example, researchers at the Stanford University School of Medicine found that human swarms were significantly more accurate in diagnosing pneumonia than a state-of-the-art software-only machine-learning system. ${ }^{32}$ Human swarms of just eight radiologists achieved $82 \%$ accuracy in diagnosing pneumonia, while the machine-learning AI system achieved $60 \%$ diagnostic accuracy. The Stanford study highlights how swarming enables even small groups of experts to pool their collective intelligence to outperform AI systems that rely on machine learning. 
Comparing ASI with Other Methods of Pooling Intelligence

So, how do swarms differ from other methods of pooling human intelligence that have been used to shed light on known unknowns - when there are few historical data available and the future cannot be extrapolated from what is known? As noted above, when bees are faced with known unknowns (e.g., where to locate the hive), they pool their intelligence and arrive at a decision that is based on interactions with group members. Moreover, as the swarm collaborates to converge on a solution, their behavior suppresses individual error and amplifies more beneficial solutions. This is due do the parallel nature in which knowledge is pooled—all participants are interacting simultaneously. In contrast, when businesses are faced with known unknowns, they often use surveys or crowds, assemble groups, or use prediction markets to aggregate intelligence and to make decisions. While these approaches have benefits, each also has important limitations as discussed below.

Surveys. When faced with known unknowns, decision makers often use familiar methods of aggregating attitudes, opinions, and preferences that rely on surveys to gain insight about and to seek direction from stakeholders. Surveys pool knowledge by aggregating independent input from participants relatively quickly and cheaply to find frequent or average responses. For example, survey research is commonly used to support new product launch, where demand for new products is predicted from responses to questions about the purchase category, the product concept, and purchase intentions. ${ }^{33}$ Survey results can misinform the decision to launch because they do not reflect true purchase intentions. ${ }^{34}$ More generally, surveys are subject to measurement error and various sources of bias, such as sampling, common methods, social 
desirability, and non-response, which can impact the accuracy of the results. ${ }^{35}$ Finally, determining the confidence that participants have in their responses is accomplished through self-report measures, which are known to produce overconfident estimates. ${ }^{36}$

In contrast, ASI is an intelligent system of networked participants, where the input from each individual is not a choice for a particular option on a survey measure. Instead, ASI enables each participant to express his or her own tacit and explicit knowledge with respect to the options presented and respond to the combined tacit and explicit knowledge of the collective. The outcome is the result of a real-time negotiation between swarm participants. Research demonstrates that pooling the intelligence of humans through the ASI platform produces more accurate results than surveys. In one recent study, financial traders were surveyed weekly about the trends of four common market indices (SPX, GLD, GDX, and CRUDE). After completing the survey individually, they convened online as a real-time swarm to answer the same questions synchronously. Across three months of weekly testing, results showed a $26 \%$ increase in accuracy when predicting weekly trends as a swarm. ${ }^{37}$

Groups. Businesses often use groups to make decisions. ${ }^{38}$ There are multiple ways in which groups can collaborate to pool knowledge relevant to their discussions about known unknowns. Group members can engage with each other in a parallel process, such as an unstructured faceto-face discussion in which participants are consistently responding to each other. Groups can also engage in more structured serial processes such as the nominal group or Delphi techniques, in which knowledge is pooled sequentially. ${ }^{39} \mathrm{Such}$ groups are selected based on the expertise of the participants, but limited resources and coordination costs place an upward limit on the number of diverse perspectives available to a group. ${ }^{40}$ 
Using groups to make decisions about known unknowns is not without drawbacks. Groups with 12 or more members experience difficulty having effective interaction, knowledge exchange, and participation due to process losses and coordination costs. ${ }^{41}$ Even smaller groups aided through group decision support systems can struggle to reach an effective decision, failing to use the diverse information available to them..$^{42}$ Groups are also limited because the pool of relevant experts is often relatively small and many experts within an organization rely on the same information source. ${ }^{43}$ There is also no systematic way to weight the importance of information supplied by members. ${ }^{44}$ As a result, self-ratings or perceptual cues (e.g., communication ability) are used to evaluate the confidence of members, both of which are problematic assessments. ${ }^{45}$ Others have observed that in many instances, non-experts can outpredict experts because they are less likely to hold faulty mindsets or to have an ego to protect. ${ }^{46}$

Barriers exist to pooling intelligence in groups, often because members may be discouraged from sharing or they censor themselves. These barriers can stem from biases, inequality in status, conformity to norms, or fear of appearing foolish by attempting to verbalize inexpressible tacit knowledge. ${ }^{47}$ Business decision-making groups often privilege communications styles that are logical, rational, and evidence-based. ${ }^{48}$ Consequently, preferences or opinions that are based on tacit knowledge and presented without data-driven evidence may be disregarded by the group. ${ }^{49}$

Diversity in decision-making groups can also present a challenge. While the potential benefits of diverse membership in groups is well-supported, actually realizing these benefits is less common. ${ }^{50}$ Team membership that reflects diversity along observable differences (e.g., age, gender, race, sexual orientation) leads to more emotion-based disagreements, which can hinder how tacit knowledge is heard and valued by the group. ${ }^{51}$ While seeking group consensus can 
overcome some of these limitations, use of consensus-building in decision-making teams is hindered by the requisite time and effort..$^{52}$

ASI is not subject to many of the same limitations of groups. First, swarming does not require explicit communication. Second, ASI enables parallel processes of deliberation, which limit herding. Third, swarms can function effectively, include an incredibly diverse array of individuals, and reach a decision (generally, within 60 seconds) with a dozen or more participants. Moreover, swarms consisting of as few as three members have been shown to outperform equally sized groups. ${ }^{53}$ Fourth, the anonymity that ASI affords masks power differentials among participants and can promote more equal participation across all swarm members. Each individual's contribution to the swarm is weighted based on his or her real-time confidence. ${ }^{54}$ In sum, swarms have a greater capacity than groups to include and support a large array of diverse participants to converge on a collective response.

Crowds. Organizations can pool the collective intelligence of hundreds, even thousands, of people from all over the world by harnessing crowds. ${ }^{55}$ The aggregated opinions, predictions, or votes of a large diverse, decentralized, and independent group of people can often be more accurate than the judgments made by any of the individuals that form the group. ${ }^{56}$ Businesses have successfully deployed crowdsourcing methods in various ways. For example, they have used crowdsourcing internally to engage employees in strategy development. ${ }^{57}$ Organizations have also used crowds to surface ideas and solutions, as is the case of platforms such as Climate CoLab, InnoCentive, Spigit, and Brightidea. ${ }^{58}$

While popular, using crowds to pool intelligence also has limitations. ${ }^{59}$ First, contributions to crowd-based platforms are often provided serially and may not be independent, such that seeing the contributions of others can produce herding behaviors. ${ }^{60}$ Second, the 
wisdom-of-the-crowd effect requires motivating large numbers of people with differing opinions to contribute to the system. ${ }^{61}$ Business decisions that require local and specialized knowledge may not be well-suited to crowdsourcing, as the group with the relevant knowledge is simply too small. ${ }^{62}$ Third, too many contributions to crowdsourcing platforms can be problematic. Sifting through and evaluating large numbers of crowdsourced solutions can take years, as well as considerable human and financial resources. ${ }^{63}$ The enormity of the task can focus decision makers' attention on ideas that are most familiar to them, which inhibits the organization from making use of the most promising novel ideas and runs contrary to the purpose of crowdsourcing platforms. ${ }^{64}$ Fourth, to facilitate decision making, many crowdsourcing platforms encourage the practice of upvoting crowdsourced ideas, which is subject to herding processes (social influence and information cascades) due to the sequential nature of these votes. Seeing the votes or information provided by previous participants can diminish the diversity of information considered; cause the crowd to draw a conclusion that is incorrect; and boost the crowd's confidence in an incorrect conclusion. ${ }^{65}$ Algorithmic bias in the display of many choices can also hinder the quality of rankings. ${ }^{66}$

ASI is able to address some of these limitations. While crowds require large numbers of participants, ASI is capable of producing accurate decisions with both a small and large number of participants. In addition, ASI is less susceptible to herding because individual contributions are not visible. ${ }^{67}$ Finally, researchers have demonstrated that aggregating the input of humans via ASI is capable of producing more accurate forecasts than large-scale crowds. ${ }^{68}$

Prediction markets. Prediction markets are organized to trade the unknown outcome for an event or topic. They pool the intelligence of participants—each of whom possesses unique knowledge - and the prices of the exchange-traded contracts reflect the aggregated knowledge of 
what participants believe to be the most likely outcome ${ }^{69}$ Each market transaction is conducted between a single buyer and a single seller, and trades are executed in sequence to engage a full population. Prediction markets function best with large numbers of participants, with a minimum of $50 .{ }^{70}$ The financial incentives or consequences in prediction markets spur people to find and act on the best information and to learn from each other. Moreover, markets enable confidence to be inferred implicitly through the volume of trades, which can be used to weight the contribution of each participant. ${ }^{71}$ The accuracy of prediction markets for outcomes involving geopolitical or sporting events has spurred growing interest in using corporate prediction markets to engage employees, customers, regulators, stockholders, and suppliers in making predictions about project outcomes, sales forecasts, product features, and other types of strategic decisions. ${ }^{72}$

There are challenges associated with using prediction markets to address known unknowns. First, markets require large numbers of active and informed participants. In corporate settings, the need for confidentiality or the number of available personnel may limit participation. ${ }^{73}$ Second, prediction markets require a binary choice task, which is not intuitive and often poorly understood compared with more familiar rating scales found on surveys. ${ }^{74}$ Moreover, a binary outcome choice (e.g., yes/no: will a product feature reach a threshold level of interest in the market) may not offer a way of asking the questions that businesses need answered. Third, some people have difficulty translating their knowledge into a price in a prediction market. ${ }^{75}$ Fourth, because trades are sequential and markets are open until an event occurs, participants are vulnerable to social influence and information cascades (herding behaviors). ${ }^{76}$

Like prediction markets, swarms aggregate the explicit and tacit knowledge of participants. While prediction markets are well-suited for handling questions with binary choice 
sets, ASI not only handles binary questions, but also questions with many decision options. ${ }^{77}$ Unlike prediction markets, swarms do not require large numbers of financially motivated participants to make accurate predictions. In addition, swarms do not operate sequentially. Instead, they operate in parallel, which enables swarms to pool intelligence more quickly and can also filter out to a significant degree the incorrect or "noisy" information that exists at the individual level. ${ }^{78}$ However, these benefits come at the cost of requiring that all participants work synchronously together, while prediction markets can operate asynchronously. Still, researchers have demonstrated that aggregating the input of humans via ASI is capable of producing more accurate forecasts than largescale prediction markets. ${ }^{79}$

In sum, ASI includes some of the positive qualities of pooling intelligence found in surveys, groups, crowds, and prediction markets and minimizes some of the limiting aspects. In particular, three qualities of ASI — swarm size, its method of pooling intelligence, and its use of confidence scores - enable swarms to make better predictions about known unknowns than other methods. First, swarms are less restricted by size. Effective surveys, crowds, and prediction markets require a large number of participants, while the effectiveness of groups is limited to about 12 members. In contrast, ASI has outperformed these other methods by using swarms that range between 3 and 1000 participants. Second, participants in swarms pool intelligence anonymously, without communication, and in parallel with each other. These qualities insulate swarms from herding behaviors such as information cascades and social influence. The serial nature of pooling intelligence in groups, crowds, and prediction markets makes them particularly susceptible to information cascades. Third, participants in swarms are automatically assigned a real-time confidence score that augments their influence on the collective decision. The only other method of pooling intelligence that offers an implicit measure of confidence is prediction 
markets, which can use trading volume. As for surveys and crowds, if respondents' confidence in their answers is measured at all, self-report confidence measures are used, which are notoriously inaccurate. ${ }^{80}$ While groups have access to social signals of confidence (e.g., a confident communication style), these can be misinterpreted or inaccurate. These comparisons are summarized in Table 1.

What Are the Boundary Conditions for ASI?

While ASI can overcome some limitations of other approaches to pooling knowledge, the nascent research on human swarming does reveal some limitations surrounding its usefulness for making decisions about known unknowns. These relate to issues surrounding synchronicity, the number of questions asked, whether response options can be articulated for the questions being asked, and whether or not participants have some knowledge that is relevant to the domain. First, swarming requires that all participants contribute synchronously. While Swarm $A I \circledR$ is capable of connecting distributed participants, finding a time when everyone can meet may pose a challenge to organizations seeking to compose a swarm. Moreover, the need for synchronous network connectivity and either mobile or desktop devices for each participant leaves ASI more susceptible to technical issues. Second, swarming is best suited for a smaller set of questions (e.g., $<30)$ as it may be difficult to sustain engagement across all participants [Insert Table 1] with larger question sets. ${ }^{81}$ Third, ASI is optimized to enable a swarm of participants to consider a set of response options and to converge on an option that best satisfies the swarm. However, if response options cannot be articulated either in the original consideration set or through the previously discussed "top that" functionality of Swarm AI ${ }^{\circ}$, they cannot be considered by the swarm. ${ }^{82}$ Fourth, ASI is ideally suited for participants who have some knowledge about the 
topics to be decided. While participants do not need to be experts, there does need to be existing intelligence present in the swarm that can be amplified..$^{83}$ These boundary conditions inform the kinds of business decisions that ASI is well-suited to address.

\section{ASI and Business Decision Making}

Businesses and other organizations have used technology-enabled platforms to tap the wisdom of crowds and to source ideas for almost 20 years. By comparison, the use of ASI to pool the explicit and tacit knowledge of large groups of people to make decisions or predictions about known unknowns is nascent. Next, we describe two focused case studies, showing how businesses have used ASI to pool human intelligence. The first demonstrates how a swarm more accurately forecasted sales than the traditional forecasting methods used by the business. In the second case study, we show how ASI brought together employees from across an organization to arrive at the strategic priorities that mattered most to the collective. This case illustrates the way in which ASI can facilitate group decision making, improve employee engagement, and also provide valuable post-processing information that provides insights into the decision process. These case studies illustrate a range of possibilities for application of ASI.

\section{Bustle Case: Human Swarms Forecast Sales Better Than Surveys}

Accurate sales forecasting is critical to businesses of all sizes, enabling teams to project revenue, prioritize marketing, plan distribution, and scale inventory levels. For existing products, historical data can be used to build models that can predict future sales with reasonable accuracy. For new products, however, there are no historical sales data available and predictions are likely to be made from customer interview or survey data. ${ }^{84}$ In the highly competitive fashion retail 
market, with its short product life cycles and no historical data from which to develop forecasts, production and inventory decisions are often made without the benefit of accurate sales forecasts.

While AI has been explored as a means of forecasting sales in fashion retail, many companies continue to make decisions on the basis of simpler techniques, as AI models are complex and require significant resources. ${ }^{85}$ Use of ASI in this and similar decision environments offers advantages, as the accuracy of swarm results does not depend on historical data. As noted previously, the Swarm $\mathrm{AI}{ }^{\circledR}$ engine is trained on behavioral data and not on historical, subject-specific datasets. While machine learning AI can only tap into historical data sets, ASI taps into the "human database." A business simply needs to engage a group of participants who are familiar with the product category and the sales context and enable them to swarm. Expertise in forecasting, market research, fashion design, or other relevant skill sets is not required. For this reason, applying ASI to forecasting problems offers core benefits: it is easy to implement, it enables decision makers to engage populations with diverse perspectives and to combine their knowledge and insights, and it can be more effective ways than traditional methods of pooling intelligence such as surveys or polls. The following case supports use of ASI in a sales forecasting context.

Bustle Media Group is a large publisher targeting millennial women. In collaboration with one of its advertisers - a major, publicly traded U.S.-based clothing manufacturer included in the S\&P 500-Bustle sought insight into which of the sweaters in a new line of eight sweaters designed by the manufacturer for the 2018 holiday season would sell better online. Bustle decided to run a trial to compare ASI predictions with predictions based on traditional survey methodology. A panel company was used to source 45 female respondents who fit the [Insert Figure 2] demographic profile of the intended target market, which was millennial women. 
Screener questions verified that the women were interested in fashion and had no prior sales forecasting experience. Respondents were asked to complete an online survey that required them to rank order the eight sweaters from best to worst selling, using a drag and drop question format. The mean rank of each sweater across all surveys was used to generate an ordered list of sweaters. Following completion of the survey, respondents logged into the ASI platform and rank-ordered the sweaters as a swarm. A process of elimination methodology was used, where six sweater options were presented, and the least favored option was removed (Figure 2). The least favored option was replaced by one that the swarm had not yet considered, the question was repeated, and, once again, the least favored option was removed. The method required seven minutes and seven iterations to produce a ranking of all eight sweaters.

At the end of the holiday season, sales data from the clothing manufacturer were used to develop comparisons between the swarm and the survey rankings. Table 2 shows that the swarm ranked the sweaters well, with the top two swarm-ranked sweaters outperforming the bottom two, by almost $300 \%$. On the other hand, the survey ranked the sweaters poorly, such that the bottom two survey-ranked sweaters actually outsold the top two. Pooling the knowledge of the same 45 respondents to arrive at negotiated rankings as a swarm outperformed the aggregation of the swarm participants' individual survey responses. [Insert Table 2]

If the clothing manufacturer were to plan on the basis of survey rankings, it would leave the company with unsold inventory (i.e., Sweater D), which the company would have to discount in order to sell. In addition, had the company decided not to make Sweater B, which the swarm correctly placed in the top three, it would have lost potential sales of $\$ 903,569$. These results demonstrate that swarms can outperform survey methodologies as a means of answering known unknowns - which sweaters will sell better than others - and that ASI has the potential to enable 
companies to improve upon frequently used market research-based methods of forecasting sales for new products. Better sales forecasts, in turn, lead to improvements in production planning and inventory management, and to higher customer service levels through minimizing backordering and out-of-stock situations.

\section{Z Energy Case: Swarming Enables Convergence on Strategic Priorities Better Than Group} Discussion

Not all business decisions involving known unknowns have a definitively correct answer (e.g., Which candidate should we hire? What are our priorities?). To deal with these types of decisions, businesses organize decision-making processes that elicit participation and buy-inoften in the form of group discussions, surveys, polls, or votes-from key stakeholders. Getting key people in the organization to connect with decision outcomes is key to moving strategic initiatives forward and satisfaction with decision outcomes is critical to sustainable agreement and implementation. ${ }^{86}$ With vote-based decisions, individual group member satisfaction with the final group decision can be lower when initial individual preferences are different from the group choice. ${ }^{87}$ Since satisfaction with a group's decision is at the heart of sustainable agreement and implementation, real-time swarming can offer groups a significant benefit compared with traditional decision-making alternatives, such as votes and polls.

The leadership team at Z Energy, a New Zealand fuel distributor with branded service stations, was intrigued by the advantages that ASI offered over traditional group decisionmaking processes. Because participation and buy in were so important to Z Energy executives, they decided to use ASI to prioritize 23 strategic initiatives. Their goal was to tap the collective intelligence of the employees in its Finance, Technology, and Risk (FTR) group to identify the 
top five initiatives that should be explored during an FTR group offsite. Two groups within FTR were convened to prioritize strategic initiatives for the company, one comprising 61 individual contributors and one comprising 42 managers. Both employee groups included male and female employees, a wide range of ages (25-46+), and employees with varying levels of experience with the firm (ranging from $<1$ year to $7+$ years).

Two swarm sessions were held—one for each group—where employees involved in each group considered initiatives across six topic areas, which included finance-related, productivity, leadership, technology, employee engagement, and values-based initiatives. An exclusion choice methodology was used, where six strategic initiatives were presented in the decision space at a time. Swarm participants were asked to agree on a least preferred strategic option, which was then replaced with another option. Swarms were repeated until all strategic initiatives were considered, and the swarm arrived at a final ranking. Each employee group swarmed 22 times to rank the 23 strategic initiatives.

Figure 3 shows how the group of 61 individual contributors ranked the ten strategic options. The figure shows two different rankings: ordinal and scaled. Confidence data, derived from the pull exerted by participants' magnets on each of the decision options, were processed by the AI engine and used to produce a more nuanced and informative ranking of the strategic options. The scaled ranking shows the relative distance between each of the strategic options and reveals that the swarm's preference for some of the strategic options was very close, while the swarm's preference for other options was farther apart. As can be seen in Figure 3, not only did the swarm rank Commercial Thinking first, but also the swarm ranked it a strong first. The swarm ranked ERP as a fairly weak second priority (with a scaled ranking of 2.7), which was very close to Customer Focus (with a scaled ranking of 3.02). Figure 3 also shows that the 
group's preference for the bottom three strategic priorities - Collaboration, Senior Leadership, and Change Management—was virtually indistinguishable, with rankings of 9.94, 9.97, and 10, respectively. For interested readers, additional post-processing diagnostics that were made available to Z Energy's leadership and employee teams are presented in an appendix available in the online version of this article.

The leadership team at Z Energy was interested in understanding employee priorities and the swarm results provided those insights. While there is no "ground truth" associated with the ranking of strategic initiatives, the use of ASI offered opportunity for a fairly large group of stakeholders to consider their priorities collectively, and to establish a ranking in a relatively short period of time that reflected their pooled intelligence and best satisfied the group. The postprocessing charts [see Figure 3] and information provided valuable insights into the group's decision-making process and highlighted opportunities for discussion. This was emphasized in the following quotation from Jason Sutherland, Business Program Manager:

By using ASI, we engaged employees to make 23 strategic priority decisions in the space of an hour. Swarming helped us to narrow our focus on what really mattered. Rather than individuals getting after what they deemed to be important, using Swarm technology brought us together to get after what mattered to us as a unit. As a result, we have improved employee engagement.

The acceptance of decisions by affected stakeholders is often an important measurement of the quality of a decision. For important issues, decision acceptance is greater with direct participation ${ }^{88}$ Increased legitimacy and acceptance of decisions is associated with improved motivation and performance. ${ }^{89} \mathrm{~A}$ low-quality solution that has good acceptance can be more effective than a higher-quality solution that lacks acceptance. ${ }^{90}$ 
Discussion

The field of AI has long sought to mimic the intelligence found in nature. Human intelligence serves as a model for many of these approaches; however, ASI demonstrates that the answer to building systems capable of doing things that individual humans cannot do may also be found in other forms of intelligence in nature. By using machines to enable humans to mimic the swarm intelligence found in insects, ASI represents a blending of machine and human strengths that enables groups of humans to amplify the intelligence of the system. Implications for future research are presented in an appendix available in the online version of this article. Implications for practice are presented below.

Implications for Practice: When to Use ASI

Decision making and prediction. Businesses need to make decisions about known unknowns, and making decisions that are even incrementally more accurate can yield significant advantages over time. ${ }^{91}$ Making business decisions requires both analytical and intuitive thinking. ${ }^{92}$ Consequently, recent calls have advocated for the development of AI solutions that can better integrate human explicit and tacit knowledge. ${ }^{93}$ This article introduces ASI, which enables human swarms to collectively reach decisions that exceed the accuracy of traditional methods of pooling human intelligence..$^{94}$

ASI offers flexibility in swarm size and composition. There is often a trade-off between using crowds and groups - should one value the expertise of a smaller group or the diversity of a large crowd? ${ }^{95}$ ASI operates efficiently under both of these conditions, quickly pooling the collective intelligence available to groups large and small. Many business decisions that involve 
known unknowns require input from members of a relatively small group of people, such as teams making hiring decisions, venture capital firms making decisions about which startups to invest in, and hedge fund managers making investment decisions. ${ }^{96}$ These kinds of questions preclude the use of prediction markets for several reasons. First, prediction markets function best with larger groups. ${ }^{97}$ Second, to engage a large enough group, businesses would have to share proprietary information or market knowledge broadly, which decision makers may be opposed to. Typically small, internal groups deliberate over these types of questions, where herding behaviors can limit the knowledge pooled in the group. ${ }^{98}$ In contrast, for decisions that require input from a small, internal group of people with specialized knowledge, ASI not only offers a quick and efficient method of pooling their intelligence but also limits herding behaviors. ASI is also particularly suitable when the number of participating decision makers is too large to function effectively as a group, but is also too small to function well as a crowd or prediction market. ASI's upper limit on group size is unknown. The largest swarm size to date included 1,000 people, indicating that ASI offers the potential to engage very large groups of diverse and distributed participants.

Performance tracking and feedback. ASI also automatically captures extensive real-time data about individual and swarm behavior as the group converges upon a decision. These data can be used to provide rapid feedback to swarm participants. Tracking predictions and providing feedback is an essential way of improving forecasting performance. ${ }^{99}$ When individuals receive timely feedback on the accuracy of their predictions and, more importantly, when they spend time reflecting on why they made those choices (e.g., the assumptions made or the data used), learning occurs. The post-processing capabilities of Swarm AI ${ }^{\circledR}$ provide a way to visualize and 
disseminate instant feedback on the dynamics that occur during a swarm. For example, the $\mathrm{Z}$ Energy case show that people's starting response is often not where they conclude over the duration of the swarm. Some participants shift their perspectives multiple times, while others demonstrate stronger confidence in their initial responses. Review of the real-time data recorded by ASI can be used to discuss the various rationales that participants had during the decisionmaking process. These data can also be used to record the accuracy of individual and group judgments, which can be used to determine how much weight they are assigned in the future. ${ }^{100}$

\section{Conclusions}

Much of the current discourse on AI is focused on how machine-learning systems help humans make better business decisions. ${ }^{101}$ Machine learning AI systems are designed to accomplish specific tasks, by accessing and analyzing enormous volumes of data and providing intelligence so that humans can make faster, more efficient, and more effective decisions. The fear is that, as advances in AI are made, systems could engage in "recursive self-improvement" and trigger an intelligence explosion that surpasses human intellect. At this point, humans will no longer be needed to develop, train, and manage various AI applications or interpret results and make decisions. ${ }^{102}$

We have demonstrated how ASI can amplify the intelligence of relatively small groups of people, such that they exceed the results returned by surveys, polls, prediction markets, and machine learning AI. With the capacity to connect thousands of people around the world as a unified intelligence - a "brain of brains"-ASI is a kind of Supermind that has the potential to enable organizations to capitalize on the diversity, wisdom, and knowledge available in large teams to derive more accurate answers to important business questions, to make better 
predictions, and to make more effective decisions. ${ }^{103}$ Moreover, because the ASI interface enables swarm participants to remain anonymous, individual swarm members are not subject to the status or reputational pressures that prevent them from sharing knowledge, opinions, and experience that are not widely held or that contradict more forceful or higher-ranking speakers, as they often are in face-to-face team meetings. Using ASI to support decision making means that the totality of the expertise in the swarm is available to organizations or team leaders. In addition, while traditional decision-making methods, such as polls and votes, can be polarizing, ASI provides a means for enabling groups to explore a decision space and to find common ground. Finally, because swarms converge upon a unified solution together, they do not amplify individual errors or fall victim to herding effects.

Emerging research on ASI encourages researchers and practitioners to think more broadly about the potential of AI and expands the discourse. ${ }^{104}$ Rather than focusing on a narrative where computers will eventually do most things by themselves, ASI reinforces the fact that, throughout history, human achievements have required the work of groups of people. ASI directs attention on how we might enhance human capabilities through AI, rather than replacing them. Moreover, the cases described above illustrate how ASI, even in its nascent state, can outperform traditional methods of supporting group decisions, such as votes and polls; enable groups to reach decisions that individual participants are more satisfied with; amplify the intelligence of a group; and surpass the intelligence of machine learning AI.

\section{Declaration of Conflicting Interests}

The author(s) declared no potential conflicts of interest with respect to the research, authorship, and/or publication of this article. 
Funding

The author(s) received no financial support for the research, authorship, and/or publication of this article.

Author Biographies

Lynn Metcalf is a professor of Entrepreneurship in Orfalea College of Business at California Polytechnic State University, San Luis Obispo, and Faculty Fellows Director at the Cal Poly Center for Innovation \& Entrepreneurship (email: 1metcalf@calpoly.edu).

David A. Askay is an assistant professor of Communication Studies in College of Liberal Arts at California Polytechnic State University, San Luis Obispo, and Faculty Fellow at the Cal Poly Center for Innovation \& Entrepreneurship (email: daskay@,calpoly.edu).

Louis B. Rosenberg is CEO of Unanimous AI, San Francisco, CA and is an inventor and entrepreneur. He has also been a tenured professor at California Polytechnic State University, San Luis Obispo (email: 1ouis@unanimous.ai).

Notes

1. See Ajay Agrawal, Joshua Gans, and Avi Goldfarb, Prediction Machines: The Simple Economics of Artificial Intelligence (Boston, MA: Harvard Business Review Press, 2018); James

Wilson and Paul R. Daugherty, "Collaborative Intelligence: Humans and AI Are Joining Forces," Harvard Business Review, 96/4 (July/August 2018): 115-123.

2. See Massimo Garbuio and Nidthida Lin, “Artificial Intelligence as a Growth Engine for Health Care Startups: Emerging Business Models,” California Management Review, 61/2 
(Winter 2019): 59-83; Brad Power, "How AI Is Streamlining Marketing and Sales," Harvard Business Review Digital Articles, June 12, 2017, https://hbr.org/2017/06/how-ai-is-streamliningmarketing-and-sales; Dave Sutton, "How AI Helped One Retailer Reach New Customers," Harvard Business Review Digital Articles, May 28, 2018, https://hbr.org/2018/05/how-ai helped-one-retailer-reach-new-customers; Dayong Wang, Aditya Khosla, Rishab Gargeya, Humayun Irshad, and Andrew H. Beck, "Deep Learning for Identifying Metastatic Breast Cancer," arXiv preprint, arXiv:1606.05718, 2016.

3. Agrawal et al., op. cit.

4. Erich N. Brockmann and William P. Anthony, "Tacit Knowledge and Strategic Decision Making," Group \& Organization Management, 27/4 (December 2002): 436-455; Robert M Grant, "Toward a Knowledge-Based Theory of the Firm," Strategic Management Journal, 17/S2 (January 1996): 109-122; Dorothy Leonard and Sylvia Sensiper, "The Role of Tacit Knowledge in Group Innovation,” California Management Review, 40/3 (April 1998): 112-132; Ikujiro Nonaka, “A Dynamic Theory of Organizational Knowledge Creation,” Organization Science, 5/1 (February 1994): 14-37; Jose Castillo, “A Note on the Concept of Tacit Knowledge,” Journal of Management Inquiry, 11/1 (March 2002): 46-57.

5. Richard K. Wagner and Robert J. Sternberg, "Practical Intelligence in Real-World Pursuits: The Role of Tacit Knowledge," Journal of Personality and Social Psychology, 49/2 (August 1985): 436-458.

6. Nonaka, op. cit.; Castillo, op. cit. The list is intended to be illustrative, rather than exhaustive. For a typology of tacit knowledge, see Castillo, op. cit. 
7. Michael Polanyi, “The Logic of Tacit Inference,” Philosophy, 41/155 (January 1966): 1-18;

Louis Sanzogni, Gustavo Guzman, and Peter Busch, “Artificial Intelligence and Knowledge

Management: Questioning the Tacit Dimension,” Prometheus, 35/1 (September 2017): 37-56.

8. Ethan M. Rudd, Lalit P. Jain, Walter J. Scheirer, and Terrance E. Boult, "The Extreme Value Machine," IEEE Transactions on Pattern Analysis and Machine Intelligence, 40/3 (March 2018): 762-768.

9. Thomas Davenport, "Rise of the Strategy Machines," MIT Sloan Management Review, 58/1 (Fall 2016): 13-16; Adam Borison and Gregory Hamm, "Prediction Markets: A New Tool for Strategic Decision Making," California Management Review, 52/4 (Summer 2010): 125-141.

10. For a discussion of explicit and tacit knowledge and optimal business performance, see Roger Martin, The Design of Business: Why Design Thinking is the Next Competitive Advantage (Boston, MA: Harvard Business Press, 2009); Ikujiro Nonaka and Hirotaka Takeuchi, The Knowledge-Creating Company (Oxford, UK: Oxford University Press, 1995).

11. Paul Schoemaker and Philip E. Tetlock, "Building a More Intelligent Enterprise," MIT Sloan Management Review, 58/3 (Spring 2017): 28-38.

12. Louis Rosenberg, Matthew Lungren, Safwan Halabi, Gregg Willcox, David Baltaxe, and Mimi Lyons, “Artificial Swarm Intelligence Employed to Amplify Diagnostic Accuracy in Radiology," IEEE Information Technology, Electronics and Mobile Communication Conference, Vancouver, BC, Canada, December, 2018, pp. 1186-1191.

13. Thomas W. Malone, Superminds: The Surprising Power of People and Computers Thinking Together (New York, NY: Little, Brown, 2018).

14. Wilson and Daugherty, op. cit. In their research involving 1500 companies, Wilson and Daugherty found that companies achieve the most significant performance improvements when 
humans and machines collaborate together. Examples of performance improvements include product design, employee and customer engagement, manufacturing, and medical diagnoses. They and others suggest that AI can amplify human intelligence, promote better decision making by providing ready access to relevant information, and augment the physical capabilities of humans. See also Agrawal et al., op. cit.; Malone, op. cit.

15. William Sulis, "Fundamental Concepts of Collective Intelligence," Nonlinear Dynamics, Psychology, and Life Sciences, 1/1 (January 1997): 35-53.

16. Iain D. Couzin, "Collective Cognition in Animal Groups," Trends in Cognitive Sciences, 13/1 (January 2009): 36-43; Christos C. Ioannou, "Swarm Intelligence in Fish? The Difficulty in Demonstrating Distributed and Self-Organised Collective Intelligence in (Some) Animal Groups," Behavioral Processes, 141/2 (August 2017): 141-151.

17. Constantin-Bala Zamfirescu and Florin Gheorghe Filip, "Swarming Models for Facilitating Collaborative Decisions," International Journal of Computers Communications \& Control, 5/1 (March 2010): 125-137; Francis Heylighen, "Stigmergy as a Universal Coordination Mechanism I: Definition and Components," Cognitive Systems Research, 38 (June 2016): 4-13.

18. Eric Bonabeau, Marco Dorigo, and Guy Théraulaz, Swarm Intelligence: From Natural to Artificial Systems (Oxford, UK: Oxford University Press, 1999); Simon Garnier, Jacques Gautrais, and Guy Theraulaz, “The Biological Principles of Swarm Intelligence," Swarm Intelligence, 1/1 (June 2007): 3-31; Ioannou, 2017, op. cit.

19. Eric Bonabeau and Christopher Meyer, "Swarm Intelligence: A Whole New Way to Think about Business," Harvard Business Review, 79/5 (May 2001): 106-115.

20. Csaba Virágh, Gábor Vásárhelyi, Norbert Tarcai, Tamás Szörényi, Gergő Somorjai, Tamás Nepusz, and Tamás Vicsek, "Flocking Algorithm for Autonomous Flying Robots," 
Bioinspiration \& Biomimetics, 9/2 (May 2014): 025012; Michael Rubenstein, Alejandro Cornejo, and Radhika Nagpal, "Programmable Self-Assembly in a Thousand-Robot Swarm," Science, 345/6198 (August 2014): 795-799.

21. James Marshall, Rafal Bogacz, Anna Dornhaus, Robert Planqué, Tim Kovacs, and Nigel R. Franks, "On Optimal Decision-Making in Brains and Social Insect Colonies," Journal of the Royal Society Interface, 6/40 (February 2009): 1065-1074; Louis B. Rosenberg, “Human Swarming, A Real-Time Method for Parallel Distributed Intelligence," 2015 Swarm/Human Blended Intelligence Workshop (SHBI), IEEE Xplore, Cleveland, OH, November 2015, pp. 1-7, doi:10.1109/SHBI.2015.7321685.

22. Marshall et al., op. cit.; Thomas D. Seeley and Susannah C. Buhrman, "Nest-Site Selection in Honey Bees: How Well Do Swarms Implement the 'Best-of-N' Decision Rule?’ Behavioral Ecology and Sociobiology, 49/5 (April 2001): 416-427; Thomas D. Seeley and P. Kirk Visscher, "Choosing a Home: How the Scouts in a Honey Bee Swarm Perceive the Completion of their Group Decision Making," Behavioral Ecology and Sociobiology, 54/5 (September 2003): 511520; Thomas D. Seeley, P. Kirk Visscher, Thomas Schlegel, Patrick M. Hogan, Nigel R. Franks, and James A. R. Marshall, "Stop Signals Provide Cross Inhibition in Collective DecisionMaking by Honeybee Swarms,” Science, 335/6064 (January 2011): 108-111.

23. A quorum results from an intuitive sense of when a decision has reached a threshold of social support, which produces better collective decisions. For a discussion of quorum sensing in organizations, see Teppo Felin and Thomas C. Powell, "Designing Organizations for Dynamic Capabilities," California Management Review, 58/4 (Summer 2016): 87-88. For a review of quorum sensing in social animals, see David Sumpter, Collective Animal Behavior (Princeton, NJ: Princeton University Press, 2010). 
24. Seeley and Buhrman, op. cit.

25. Hélène L. Gauchou, Ronald A. Rensink, and Sidney Fels, "Expression of Nonconscious Knowledge via Ideomotor Actions," Consciousness and Cognition, 21/2 (June 2012): 976-982. In addition, effective and efficient consensus decision making can be achieved in human groups through spatial movement without verbal communication, even when a small minority of participants have information or when participants have conflicting information. See John R. G. Dyer, Christos C. Ioannou, Lesley J. Morrell, Darren P. Croft, Iain D. Couzin, Dean A. Waters, and Jens Krause, “Consensus Decision Making in Human Crowds," Animal Behavior, 75/2 (February 2008): 461-470.

26. Herding behavior is an umbrella term that encompasses several processes whereby individuals align their personal beliefs with those of the group. Herding processes include information cascades (when an individual ignores private information in favor of publicly stated knowledge of others) and social influence (complying with authority or conforming to others' behavior). Herding behavior is most pronounced in systems that request serial input from individuals over time, wherein a sentiment builds momentum because later participants follow the lead of earlier participants. Herding processes can impair decisions or forecasts. Herding is prevalent in financial markets, prediction markets, crowdsourcing, and group discussion. Swarming is a parallel process wherein participants are providing input anonymously and simultaneously. There are no leaders or followers, which makes swarming resilient to the negative effects of herding. For an integrated review of herding, refer to Ramsey M. Raafat, Nick Chater, and Chris Frith, "Herding in Humans," Trends in Cognitive Sciences, 13/10 (September 2009): 420-428; for examples of how herding impairs decision making, see Ivo Welch, “Sequential Sales, Learning, and Cascades," The Journal of Finance, 47/2 (June 1992): 695-732; 
Sushil Bikhchandani, David Hirshleifer, and Ivo Welch, "Learning from the Behavior of Others: Conformity, Fads, and Informational Cascades," Journal of Economic Perspectives, 12/3 (Summer 1998): 151-170; Robert B. Cialdini, and Noah J. Goldstein, “Social Influence: Compliance and Conformity," Annual Review of Psychology, 55 (February 2004): 591-621; Chris D. Frith and Uta Frith, "Mechanisms of Social Cognition," Annual Review of Psychology, 63 (August 2012): 287-313.

27. The ASI confidence scores mimic the behavior of honey bees, where body vibrations not only encode the direction and distance to possible colony sites (a decision option) along with the strength of support for that site (confidence). Prediction markets also use an implicit measure of confidence, namely, trading volume. Implicit measures of confidence are believed to be more accurate than self-report measures, because participants tend to be overconfident. See Andreas Graefe and Christof Weinhardt, "Long-Term Forecasting with Prediction Markets: A Field Experiment on Applicability and Expert Confidence," The Journal of Prediction Markets, 2/2 (September 2008): 71-91.

28. For a detailed description and video of swarm intelligence, see "What Is Swarm Intelligence,” accessed March 22, 2019 https://unanimous.ai/what-is-si/.

29. While common sense suggests that an individual's first response is inclusive of all their best information, research suggests otherwise. Forcing someone to make a second judgment contributes additional information, such that averaging the two responses is more accurate than either one alone. This suggests that individual judgments are sampled from an internal probability distribution, showing value in averaging multiple within-person responses. ASI captures this notion through evaluating the movement of each participant's magnet. See Edward Vul and Harold Pashler, "Measuring the Crowd within: Probabilistic Representations within 
Individuals," Psychological Science, 19/7 (July 2008): 645-647. In addition, several rounds of reevaluating one's judgment after being exposed to the mean judgment of others in a decentralized network increases the overall judgment accuracy of the group. See Joshua Becker, Devon Brackbill, and Damon Centola, "Network Dynamics of Social Influence in the Wisdom of Crowds," in Proceedings of the National Academy of Sciences, 114/26 (June 2017): E5070E5076. ASI operates similarly in that the puck's movement represents the changing collective judgment of the swarm; however, ASI does so in real time.

30. Cass R. Sunstein and Reid Hastie, "Making Dumb Groups Smarter," Harvard Business Review, 92/12 (December 2014): 19-26; Daniel Kahneman, Dan Lovallo, and Olivier Sibony, "Before You Make that Big Decision” Harvard Business Review, 89/6 (June 2011): 50-60. 31. Louis Rosenberg, Niccolo Pescetelli, and Gregg Willcox, “Artificial Swarm Intelligence Amplifies Accuracy When Predicting Financial Markets,” 2017 IEEE 8th Annual Ubiquitous Computing, Electronics and Mobile Communication Conference, IEEE Explore, New York, NY, January 8, 2017, pp. 58-62; Louis Rosenberg and Gregg Willcox, “Artificial Swarms Find Social Optima," 2018 IEEE Conference on Cognitive and Computational Aspects of Situation Management, IEEE Explore, Boston, MA, August, 2018, pp. 174-178.

32. Louis Rosenberg, Matthew Lungren, Safwan Halabi, Gregg Willcox, David Baltaxe, and Mimi Lyons, "Artificial Swarm Intelligence Employed to Amplify Diagnostic Accuracy in Radiology,” 2018 IEEE 9th Annual Information Technology, Electronics and Mobile Communication Conference, IEEE Explore, Vancouver, BC, Canada, January 17, 2019, pp. 1186-1191.

33. Kevin J. Clancy, Peter C. Krieg, and Marianne McGarry Wolf, Market New Products Successfully: Using Simulated Test Market Technology (Lanham, MD: Lexington Books, 2006). 
34. Teck-Hua Ho and Kay-Yut Chen, "New Product Blockbusters: The Magic and Science of Prediction Markets," California Management Review, 50/1 (Fall 2007): 144-158.

35. Robert M. Groves, Floyd J. Fowler Jr. Mick P. Couper, James M. Lepkowski, Eleanor Singer, and Roger Tourangeau, Survey Methodology (Hoboken, NJ: John Wiley, 2009); Stephanie Booth-Kewley, Jack E. Edwards, and Paul Rosenfeld, "Impression Management, Social Desirability, and Computer Administration of Attitude Questionnaires: Does the Computer Make a Difference?” Journal of Applied Psychology, 77/4 (August 1992): 562-566;

Philip M. Podsakoff, Scott B. MacKenzie, and Nathan P. Podsakoff, "Sources of Method Bias in Social Science Research and Recommendations on How to Control It," Annual Review of Psychology, 63 (January 2012): 539-569.

36. Don A. Moore and Paul J. Healy, "The Trouble with Overconfidence," Psychological Review, 115/2 (April 2008): 502-517; Philip E. Tetlock and Dan Gardner, Superforecasting: The Art and Science of Prediction (New York, NY: Random House, 2016).

37. Rosenberg, Pescetelli, and Willcox, op. cit.

38. Andreas Graefe and J. Scott Armstrong, "Comparing Face-to-Face Meetings, Nominal Groups, Delphi and Prediction Markets on An Estimation Task," International Journal of Forecasting, 27/1 (January/March 2011): 183-195.

39. Ibid. The Delphi technique involves individually polling a smaller number (10-18) of experts on uncertain future events. Responses are iteratively aggregated and presented back to the experts individually until diverse opinions are narrowed. The Delphi technique can, in some instances, produce better judgments than other methods like prediction markets or crowdsourcing. 
40. Andrew Flostrand, "Finding the Future: Crowdsourcing Versus the Delphi Technique," Business Horizons, 60/2 (March/April 2017): 229-236.

41. Ivan D. Steiner, "Models for Inferring Relationships between Group Size and Potential Group Productivity,” Behavioral Science, 11/4 (July 1966): 273-283; Mark Elliott, “Stigmergic Collaboration: A Framework for Understanding and Designing Mass Collaboration," in Mass Collaboration and Education, ed. Ulrike Cress, Johannes Moskaliuk, and Heisawn Jeong (Cham, Switzerland: Springer International, 2016), pp. 65-84.

42. Alan R. Dennis, "Information Exchange and Use in Small Group Decision Making," Small Group Research, 27/4 (November 1996): 532-550.

43. Ho and Chen, op. cit.

44. Ibid.

45. Ibid.; Asher Koriat, "When Are Two Heads Better than One and Why?" Science, 336/6079 (April 2012): 360-362.

46. Tetlock and Gardner, op. cit.

47. Daina Mazutis and Anna Eckardt, "Sleepwalking into Catastrophe: Cognitive Biases and Corporate Climate Change Inertia," California Management Review, 59/3 (Spring 2017): 74108; Leonard and Sensiper, op. cit.

48. Mazutis and Anna Eckardt, op. cit.; Leonard and Sensiper, op. cit. 49. Ibid.

50. Elizabeth Mannix and Margaret A. Neale, "What Differences Make a Difference? The Promise and Reality of Diverse Teams in Organizations," Psychological Science in the Public Interest, 6/2 (October 2005): 31-55; Adam D. Galinsky, Joe C. Magee, M. Ena Inesi, and Deborah H. Gruenfeld, "Power and Perspectives Not Taken," Psychological Science, 17/12 
(December 2006): 1068-1074; Priya Raghubir and Ana Valenzuela, "Male-Female Dynamics in Groups: A Field Study of The Weakest Link,” Small Group Research, 41/1 (December 2010): 41-70.

51. Lisa Hope Pelled, "Demographic Diversity, Conflict, and Work group Outcomes: An Intervening Process Theory,” Organization Science, 7/6 (December 1996): 615-631.

52. Rolaynes DeStephen and Randy Y. Hirokawa, "Small Group Consensus: Stability of Group Support of the Decision, Task Process, and Group Relationships," Small Group Behavior, 19/2 (May 1988): 227-239.

53. David Askay, Lynn Metcalf, Louis Rosenberg, and Gregg Willcox, "Enhancing Group Social Perceptiveness through a Swarm-Based Decision-Making Platform," in Proceedings of the 52nd Hawaii International Conference on System Sciences, Honolulu, HI, January 2019, pp. 492-501. 54. Weighting individuals on their confidence or knowledge, as opposed to weighting all individual judgments equally, has been shown to produce improved group decisions. See Tetlock and Gardner, op. cit.

55. Eric Bonabeau, "Decisions 2.0: The Power of Collective Intelligence," MIT Sloan Management Review, 50/2 (Winter 2009): 45-52.

56. This requires a large diverse, decentralized, and independent group of people in the crowd. See James Surowiecki, The Wisdom of Crowds (New York, NY: Anchor Books, 2005). 57. Daniel Stieger, Kurt Matzler, Sayan Chatterjee, and Florian Ladstaetter-Fussenegger, "Democratizing Strategy: How Crowdsourcing Can Be Used for Strategy Dialogues," California Management Review, 54/4 (Summer 2012): 44-68.

58. Lars Bo Jeppesen and Karim R. Lakhani, "Marginality and Problem-Solving Effectiveness in Broadcast Search," Organization Science, 21/5 (September/October 2010): 1016-1033. 
59. Clintin P. Davis-Stober, David V. Budescu, Jason Dana, and Stephen B. Broomell. "When Is a Crowd Wise?” Decision, 1/2 (April 2014): 79-101.

60. Jan Lorenz, Heiko Rauhut, Frank Schweitzer, and Dirk Helbing, "How Social Influence can Undermine the Wisdom of Crowd Effect," Proceedings of the National Academy of Sciences, 108/22 (May 2011): 9020-9025; Lev Muchnik, Sinan Aral, and Sean J. Taylor, “Social Influence Bias: A Randomized Experiment," Science, 341/6146 (August 2013): 647-651.

61. Thomas W. Malone, Robert Laubacher, and Chrysanthos Dellarocas, "The Collective Intelligence Genome,” MIT Sloan Management Review, 51/3 (Spring 2010): 21-31.

62. Flostrand, op. cit.

63. Oguz A. Acar, "Motivations and Solution Appropriateness in Crowdsourcing Challenges for Innovation,” Research Policy, 48/8 (2019): 103716. doi:10.1016/j.respol.2018.11.010; Ivo

Blohm, Jan Marco Leimeister, and Helmut Krcmar, "Crowdsourcing: How to Benefit from (Too) Many Great Ideas,” MIS Quarterly Executive, 12/4 (December 2013): 199-211.

64. Acar, op. cit.

65. Lorenz et al., op. cit.; Surowiecki, op. cit., pp. 176-185.

66. Giovanni Luca Ciampaglia, Azadeh Nematzadeh, Filippo Menczer, and Alessandro Flammini, "How Algorithmic Popularity Bias Hinders or Promotes Quality," Scientific Reports, 8/1 (October 2018): 15951.

67. We note that herding behavior can still result from social influence exerted from outside ASI, such as through popular culture. Examples of social influence and herding behavior include Catherine Tucker and Juanjuan Zhang, "How Does Popularity Information Affect Choices? A Field Experiment,” Management Science, 57/5 (May 2011): 828-842; Lorenz et al., op. cit. 
68. Louis Rosenberg, David Baltaxe, and Niccolo Pescetelli, "Crowds vs Swarms, a Comparison of Intelligence," 2016 Swarm/Human Blended Intelligence Workshop (SHBI), IEEE Explore, Cleveland, OH, December 12, 2016, pp. 1-4.

69. Prediction markets fall under the umbrella term of crowdsourcing. See Chapter 3, "Crowdsourcing Fundamentals: Definition and Typology," in Enrique Estellés-Arolas, Raúl Navarro-Giner, and Fernando González-Ladrón-de-Guevara, Advances in Crowdsourcing (Cham, Switzerland: Springer International, 2015), pp. 33-48. Prediction markets, by definition, involve trades and have market prices that are visible to traders over time. See Justin Wolfers and Eric Zitzewitz, "Prediction Markets," Journal of Economic Perspectives, 18/2 (2004): 107126; Borison and Hamm, op. cit.

70. Ho and Chen, op. cit.

71. Graefe and Weinhardt, op. cit.

72. Bo Cowgill and Eric Zitzewitz, "Corporate Prediction Markets: Evidence from Google, Ford, and Firm X," The Review of Economic Studies, 82/4 (October 2015): 1309-1341; Borison and Hamm, op. cit.

73. Cowgill, op. cit.

74. Ivo Blohm, Christoph Riedl, Johann Füller, and Jan Marco Leimeister, "Rate or Trade? Identifying Winning Ideas in Open Idea Sourcing," Information Systems Research, 27/1 (March 2016): 27-48.

75. Kesten C. Green, J. Scott Armstrong, and Andreas Graefe, "Methods to Elicit Forecasts from Groups: Delphi and Prediction Markets Compared," Foresight: The International Journal of Applied Forecasting, 8 (Fall 2007): 17-20.

76. Wolfers and Zitzewitz, op. cit.; Borison and Hamm, op. cit. 
77. The Swarm.AI ${ }^{\circledR}$ decision space allows swarm participants to consider up to six alternatives simultaneously, which is within range of the number of judgments that humans are able to process simultaneously. See George A. Miller, “The Magical Number Seven, Plus or Minus Two: Some Limits on our Capacity for Processing Information," Psychological Review, 63/2 (March 1956): 81-97. When decision makers need to consider larger numbers of alternatives, an exclusion choice methodology can be used, which is described later in the Z Energy case later in this article.

78. Kevin M. Passino, Thomas D. Seeley, and P. Kirk Visscher, "Swarm Cognition in Honey Bees," Behavioral Ecology and Sociobiology, 62/3 (September 2008): 401-414; Jens Krause,

Graeme D. Ruxton, and Stefan Krause, "Swarm Intelligence in Animals and Humans," Trends in Ecology \& Evolution, 25/1 (January 2010): 28-34. Swarm decision making reduces the likelihood of herding because it takes several individuals to independently come to the same conclusion to reach a threshold for a decision.

79. Louis Rosenberg and Gregg Willcox, “Artificial Swarm Intelligence vs Vegas Betting Markets," 2018 11th International Conference on Developments in eSystems Engineering, IEEE Xplore, Cambridge, UK, February 5, 2019, pp. 36-39; Gregg Willcox, Louis Rosenberg, Rory Donovan, and Hans Schumann, "Dense Neural Network used to Amplify the Forecasting Accuracy of real-time Human Swarms," IEEE International Conference on Computational Intelligence and Communication Networks, Honolulu, HI, January 2019.

80. Seth Stephens-Davidowitz and Andrés Pabon, Everybody Lies: Big Data, New Data, and What the Internet Can Tell Us About Who We Really Are (New York, NY: HarperCollins, 2017); Tetlock and Gardner, op. cit. 
81. Similarly, respondent fatigue and inattention are issues with other methods of pooling intelligence, such as survey research, where engagement decreases and abandon rates increase as the number of questions asked increases. See Brent Chudoba, "How Much Time Are Respondents Willing to Spend on Your Survey?" https://www.surveymonkey.com/curiosity/survey_completion_times/; Kylie Brosnan, Nazila Babakhani, and Sara Dolnicar, “'I Know What You're Going to Ask Me’ Why Respondents Don’t Read Survey Questions," International Journal of Market Research, 61/4 (January 2019): 366-379. In addition, for group discussions, meeting length is also a factor in fatigue and engagement. See John Gastil, "Identifying Obstacles to Small Group Democracy," Small Group Research, 24/1 (February 1993): 5-27.

82. Recall that tacit knowledge can be difficult to convert into words or numbers. See Castillo, op. cit.

83. For example, to predict sweater sales, swarm participants should have bought or worn sweaters. If a question is posed such that a majority of swarm participants are simply guessing, then there is no intelligence to amplify and swarming will perform very similarly to any method of pooling intelligence, where respondents or participants are simply guessing.

84. Kenneth B. Kahn, “An Exploratory Investigation of New Product Forecasting Practices," Journal of Product Innovation Management, 19/2 (September 2002): 133-143; Kenneth B. Kahn, "Solving the Problems of New Product Forecasting," Business Horizons, 57/5 (September/ October 2014): 607-615.

85. A. L. D. Loureiro, V. L. Miguéis, and Lucas F. M. da Silva, "Exploring the Use of Deep Neural Networks for Sales Forecasting in Fashion Retail," Decision Support Systems, 114 (October 2018): 81-93; Shuyun Ren, Chi-leung Patrick Hui, and Tsun-ming Jason Choi, “AI- 
Based Fashion Sales Forecasting Methods in Big Data Era," in Artificial Intelligence for Fashion Industry in the Big Data Era, ed. Sébastien Thomassey and Xianyi Zeng (Singapore: Springer International, 2018), pp. 9-26.

86. Sam Kaner, Facilitator's Guide to Participatory Decision-Making, 3rd ed. (San Francisco, CA: Jossey-Bass, 2014); Wendy K. Smith, "Dynamic Decision Making: A Model of Senior Leaders Managing Strategic Paradoxes," Academy of Management Journal, 57/6 (December 2014): 1592-1623.

87. Amra Delic, Julia Neidhardt, Laurens Rook, Hannes Werthner, and Markus Zanker, "Researching Individual Satisfaction with Group Decisions in Tourism: Experimental Evidence," in Information and Communication Technologies in Tourism 2017, ed. Roland Schegg and Brigitte Stangl (Cham, Switzerland: Springer International, 2017), pp. 73-85.

88. Emanuel V. Towfigh, Sebastian J. Goerg, Andreas Glöckner, Philip Leifeld, Aniol LlorenteSaguer, Sophie Bade, and Carlos Kurschilgen, "Do Direct-Democratic Procedures Lead to Higher Acceptance than Political Representation?," Public Choice, 167/1-2 (April 2016): 4765; Arthur Jago, “From Victor Vroom, Philip Yetton, and Arthur Jago’s Normative DecisionProcess Theory to the Use of Participative Management," in Organizational Behavior 4: From Theory to Practice, ed. John B. Miner (Abingdon-on-Thames, UK: Routledge, 2015), pp. 131145.

89. Carsten K.W. De Dreu, Bernard A. Nijstad, and Daan van Knippenberg, "Motivated Information Processing in Group Judgment and Decision Making," Personality and Social Psychology Review, 12/1 (February 2008): 22-49; Norman R. Maier, "Assets and Liabilities in Group Problem Solving: The Need for an Integrative Function," Psychological Review, 74/4 (July 1967): 239-249. 
90. Maier, op. cit.

91. Schoemaker and Tetlock, op. cit.

92. Martin, op. cit., p. 6; Borison and Hamm, op. cit.

93. Mohammad Hossein Jarrahi, “Artificial intelligence and the Future of Work: Human-AI Symbiosis in Organizational Decision Making," Business Horizons, 61/4 (July/August 2018): $577-586$.

94. Louis Rosenberg, “Artificial Swarm Intelligence vs Human Experts,” 2016 International Joint Conference on Neural Networks, IEEE Xplore, Vancouver, BC, Canada, November 3, 2016; Rosenberg, Pescetelli, and Willcox, op. cit.; Rosenberg and Baltaxe, "Setting Group Priorities_-Swarms vs Votes," 2016 Swarm/Human Blended Intelligence Workshop, October 21-23, 2016; Rosenberg and Willcox, op. cit.

95. Flostrand, op. cit.

96. These are not hypothetical examples; Swarm $A I \circledR$ is used for these purposes.

97. Ho and Chen, op. cit.

98. Chris D. Frith and Uta Frith, "Mechanisms of Social Cognition," Annual Review of Psychology, 63 (January 2012): 287-313.

99. A study of over 25,000 forecasters making a million predictions concluded that organizations can improve their capacity for prediction, in part, by collecting real-time (e.g., video, transcripts) accounts of how their teams made judgments so that they can track performance and provide feedback. See Tetlock and Gardner, op. cit.; Schoemaker and Tetlock, op. cit.

100. Schoemaker and Tetlock, op. cit.

101. Agrawal et al., op. cit.; Wilson and Daugherty, op. cit. 
102. See "Benefits and Risks of Artificial Intelligence," Future of Life Institute, 2016, https://futureoflife .org/background/benefits-risks-of-artificial-intelligence/.

103. Malone, op. cit.

104. Paul R. Daugherty and H. James Wilson, Human + Machine: Reimagining Work in the Age of AI (Boston, MA: Harvard Business Press, 2018); Sam Ransbotham, David Kiron, Philipp Gerbert, and Martin Reeves, "Reshaping Business with Artificial Intelligence: Closing the Gap between Ambition and Action,” MIT Sloan Management Review, 59/1 (Fall 2017): 1-17.

FIGURE I. Software interface and Al engine enable human swarming through Swarm $A I \circledast$.

Which asset class will perform BEST in 2018, globally?

Note: $\mathrm{Al}=$ artificial intelligence. 
TABLE I. ASI Compared with Other Methods of Pooling Intelligence.

\begin{tabular}{|c|c|c|c|c|c|}
\hline Aspect & Surveys & Groups & Crowds & $\begin{array}{c}\text { Prediction } \\
\text { Markets }\end{array}$ & ASI \\
\hline $\begin{array}{l}\text { Effective } \\
\text { participant } \\
\text { size }\end{array}$ & 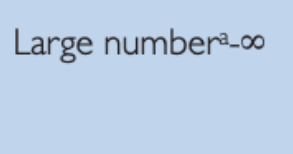 & Up to $12^{b}$ & 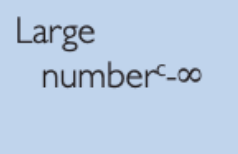 & $\begin{array}{l}\text { Large numberd } \\
\qquad(50)-\infty\end{array}$ & $3-\infty$ \\
\hline $\begin{array}{l}\text { Method of } \\
\text { pooling } \\
\text { intelligence }\end{array}$ & Aggregation & $\begin{array}{l}\text { Serial and/or } \\
\text { parallel }\end{array}$ & $\begin{array}{l}\text { Aggregation } \\
\text { and/or serial }\end{array}$ & Serial & Parallel \\
\hline $\begin{array}{r}\text { Confidence } \\
\text { evaluation }\end{array}$ & Self-report & $\begin{array}{l}\text { Self-report and } \\
\text { perceptuale }\end{array}$ & Self-report & $\begin{array}{l}\text { Trading } \\
\text { volume }^{f}\end{array}$ & Al engine \\
\hline $\begin{array}{c}\text { Susceptibility } \\
\text { to herding }\end{array}$ & $\begin{array}{l}\text { Low_knowledge } \\
\text { is independently } \\
\text { provided }\end{array}$ & Highg & Medium ${ }^{h}$ & Mediumi & Low \\
\hline
\end{tabular}

Note: ASI = Artificial Swarm Intelligence.

aOptimal size of a survey is dependent on the nature of the question and the size of the population. In some cases, a small number of participants might be effective.

blvan D. Steiner, "Models for Inferring Relationships between Group Size and Potential Group Productivity," Behavioral Science, II/4 (July 1966): 273-283.

'Thomas W. Malone, Robert Laubacher, and Chrysanthos Dellarocas, "The Collective Intelligence Genome," MIT Sloan Management Review, 5I/3 (Spring 20I0): 2I-3I.

'Teck-Hua Ho and Kay-Yut Chen, "New Product Blockbusters: The Magic and Science of Prediction Markets," California Management Review, 50/I (Fall 2007): I44-I58.

eMany social cues are used to determine confidence when interacting with people, often inaccurately. See Asher Koriat, "When are Two Heads Better than One and Why?" Science, 336/6079 (April 2012): 360-362. 'Andreas Graefe and J. Scott Armstrong, "Comparing Face-to-Face Meetings, Nominal Groups, Delphi and Prediction Markets on an Estimation Task," International Journal of Forecasting, 27/I (January/March 201 I): 183-195.

8Chris D. Frith and Uta Frith, "Mechanisms of Social Cognition," Annual Review of Psychology, 63 (August 20I2): 287-3।3.

Jan Lorenz, Heiko Rauhut, Frank Schweitzer, and Dirk Helbing, "How Social Influence can Undermine the Wisdom of Crowd Effect," Proceedings of the National Academy of Sciences, 108/22 (May 201 I): 9020-9025.

Sushil Bikhchandani, David Hirshleifer, and lvo Welch, "Learning from the Behavior of Others: Conformity, Fads, and Informational Cascades," Journal of Economic Perspectives, 12/3 (Summer 1998): I5I-I70. 
FIGURE 2. Swarms engage in process of elimination to rank order sweaters.

Which style will sell the FEWEST of this holiday season?

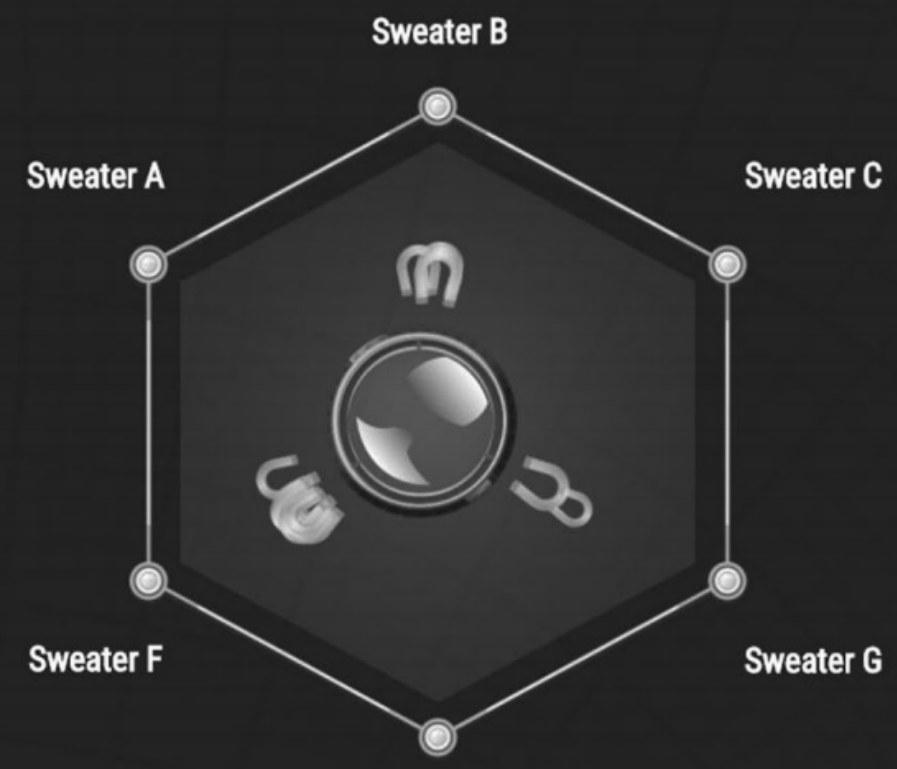

Sweater D 
TABLE 2. A Comparison of Actual Sales for the Survey and Swarm Rankings.

\begin{tabular}{|c|c|c|c|c|c|}
\hline Survey & & & Swarm & & \\
\hline Rank & Sweater & $\$ 1,434,402$ & Rank & Sweater & $\$ 1,765,640$ \\
\hline 1 & C & & 1 & C & \\
\hline 2 & $\mathrm{D}$ & & 2 & A & \\
\hline 3 & A & & 3 & B & \\
\hline 4 & G & & 4 & $\mathrm{~F}$ & \\
\hline 5 & $\mathrm{~F}$ & & 5 & $\mathrm{D}$ & \\
\hline 6 & $\mathrm{H}$ & & 6 & $\mathrm{H}$ & \\
\hline 7 & B & $\$ 1,509,410$ & 7 & $E$ & $\$ 605,841$ \\
\hline 8 & $E$ & & 8 & G & \\
\hline
\end{tabular}

FIGURE 3. Z energy strategic final priority ranking.

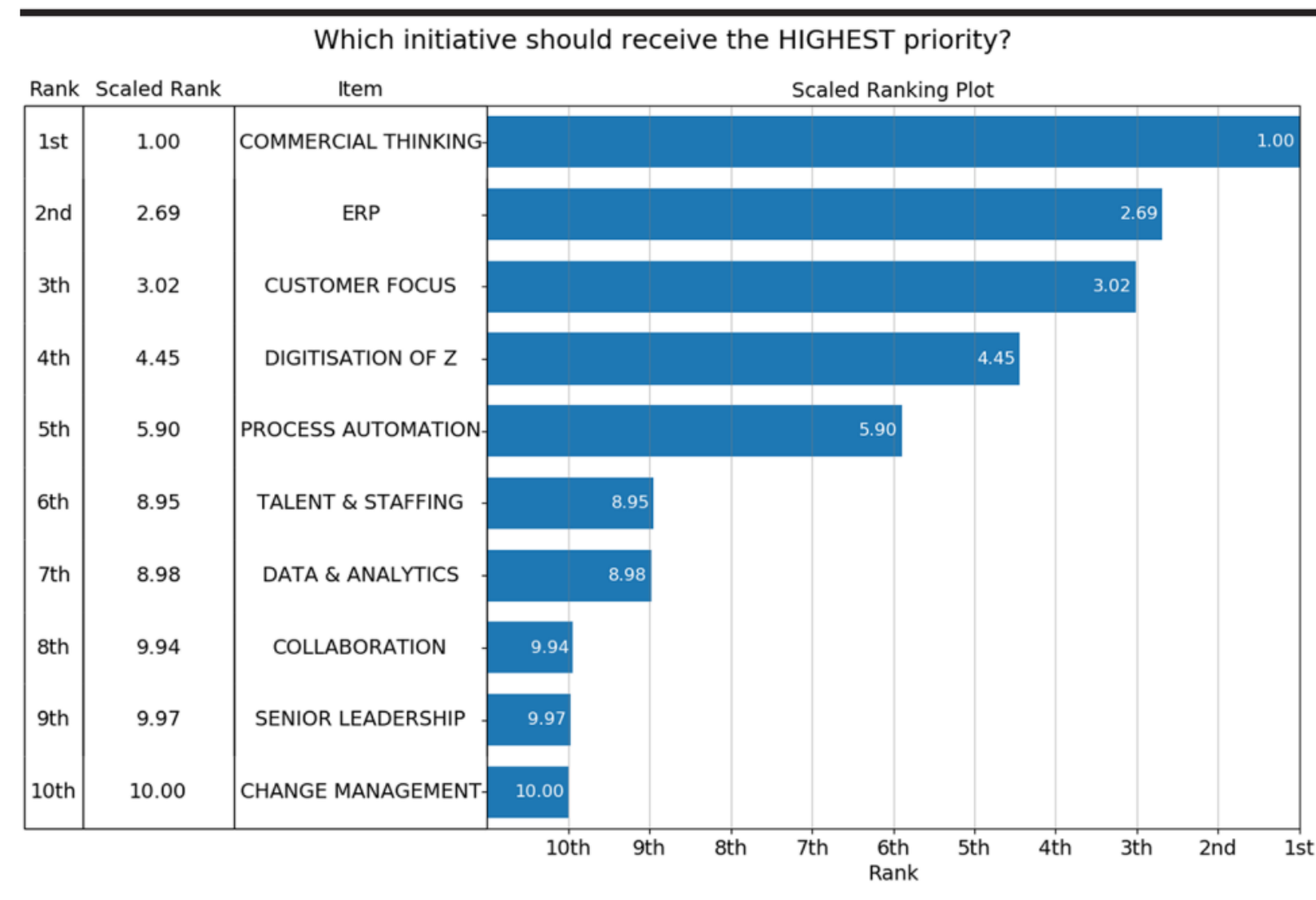

